\title{
Increased risk of synchronous colorectal lesions in patients referred for endoscopic mucosal resection of lateral spreading tumors
}

\author{
Maria Constanza TORELLA, Belén DUARTE, Mariano VILLARROEL, Juan LASA and Ignacio ZUBIAURRE
}

Received 8/3/2019

Accepted 18/6/2019

\begin{abstract}
Background - Endoscopic mucosal resection is one of the most frequent therapeutic alternatives for large colorectal lateral spreading tumors. There are few data on the prevalence of synchronous lesions on these patients. Objective - To describe the prevalence of synchronous colorectal lesions in patients referred for endoscopic mucosal resection of lateral spreading tumors $>20 \mathrm{~mm}$. Methods - We reviewed the endoscopic database of our Department and identified adult patients who were referred for the resection of a colorectal lateral spreading tumor $>20 \mathrm{~mm}$ and had a diagnostic colonoscopy performed up to six months before. The proportion of patients with at least one synchronous lesion was estimated. The following features were compared between patients with and without synchronous lesions: age, gender, bowel preparation quality and cecal intubation on index colonoscopy and therapeutic colonoscopy, serrated adenoma as index lesion. Results - From December 2016 to November 2017, we identified 70 patients who fulfilled inclusion criteria. Median size of lesions was $25 \mathrm{~mm}(20-45)$. Eighty percent were located in the right colon and $35.71 \%$ were serrated adenomas. Synchronous lesion rate was $38.57 \%$. Bowel preparation quality was similar in both groups when comparing both index and therapeutic colonoscopies. Patients with synchronous lesions had a higher proportion of serrated adenoma as index lesion than patients without synchronous lesions [51.85\% vs 25.58\%, OR $3.13(1.13-8.68), P=0.03]$. Conclusion - We found a high prevalence of synchronous lesions among patients with a large colorectal lateral spreading tumor. This risk seems to be increased if index lesions are serrated adenomas.
\end{abstract}

HEADINGS - Colorectal neoplasms. Endoscopic mucosal resection. Colonoscopy.

\section{INTRODUCTION}

Colorectal cancer $(\mathrm{CRC})$ is one of the leading causes of cancerrelated mortality worldwide ${ }^{(1)}$. It is well known that the vast majority of these tumors derive from lesions called adenomas, which can be both detected and resected at an early stage ${ }^{(2)}$. Such interventions have shown to decrease CRC mortality as well as its incidence ${ }^{(3,4)}$.

Therapeutic colonoscopy allows proper identification of colon adenomas as well as their resection. Many adenomas adopt a polypoid aspect, but a non-neglectable proportion of adenomas are classified as flat or non-polypoid ${ }^{(5)}$. Flat lesions, especially those with a diameter over $10 \mathrm{~mm}$ - which are called lateral spreading tumors constitute a diagnostic challenge for endoscopists ${ }^{(6)}$, since they can be frequently overlooked. Additionally, these lesions are predominantly located throughout the right colon, an anatomical site in which the benefit of colonoscopy for the prevention of CRC is marginal ${ }^{(7)}$.

Nowadays, most lateral spreading tumors are treated by means of endoscopic mucosal resection (EMR) ${ }^{(8)}$. This therapeutic procedure, when compared to conventional polypectomy, carries a higher risk of adverse events, such as hemorrhage or colonic perforation ${ }^{(9)}$. This is why it is a common practice to refer those patients with a diagnosis of a large lateral spreading tumor on screening colonoscopy for a subsequent programmed therapeutic EMR.

Colonoscopy as a screening method is not flawless: its diagnostic efficacy depends on bowel cleansing quality, operator accuracy in detecting mucosal lesions and endoscope withdrawal time to mention a few ${ }^{(10,11)}$. As a matter of fact, mucosal lesions - even polypoid adenomas - can be missed, which constitute a significant risk factor for interval CRC. Adenoma miss rate ${ }^{(12)}$ is cumbersome to estimate: it has been better evaluated by means of back-to-back colonoscopies under experimental settings ${ }^{(13,14)}$.

Adenoma miss rate in the context of patients with a diagnosis of a large lateral spreading tumor has not been well established; those patients referred for EMR with a recent diagnosis of lateral spreading tumors represent an ideal population for the study of such synchronous lesions.

As a consequence, we sought to describe the prevalence of synchronous colorectal lesions in patients referred for EMR of lateral spreading tumors over $20 \mathrm{~mm}$ of diameter and to determine potential variables associated with synchronous lesion detection.

\section{METHODS}

\section{Study design and population}

Study protocol was properly reviewed and approved by our Institution's Internal Review Board and the study was carried out following the ethical principles stated in the declaration of Helsinki. We reviewed our Department of Gastroenterology's endoscopic database from December 2017 to November 2018 to identify eligible subjects.

Declared conflict of interest of all authors: none

Disclosure of funding: no funding received

Hospital Británico de Buenos Aires, Gastroenterology Department, Buenos Aires, Argentina.

Corresponding author: Juan Lasa. E-mail: drjuanslasa@gmail.com 
Inclusion criteria consisted of adult patients referred to our Endoscopy Unit for the resection of a colorectal lateral spreading tumor with a diameter of at least $20 \mathrm{~mm}$ or higher. Patients would be included if diagnostic colonoscopy (index colonoscopy) was performed up to six months before EMR. We excluded patients with an incomplete index colonoscopy.

\section{Outcome measures}

According to the information provided by index colonoscopy report, we identified the index lesion to be resected; regardless of its location, endoscopists were advised to perform a complete colonoscopic examination in order to identify synchronous lesions - polypoid or non-polypoid. The proportion of patients with at least one synchronous lesion was estimated. The number, size, location and histological findings of such lesions were registered.

The following features were compared between those patients with or without synchronous colorectal lesions: age, gender, bowel preparation quality (assessed by the Boston Bowel Preparation Scale) on both index colonoscopy as well as therapeutic colonoscopy and cecal intubation in both colonoscopies. Histological findings of index lesion were also registered.

\section{Statistical analysis}

For this purpose Stata software was used (v11.1. Statacorp, College Station, Texas, USA). Categorical variables were described as percentages; numerical variables, as median with their range. We estimated the $95 \%$ confidence interval $(95 \% \mathrm{CI})$ of synchronous lesion rate. For the comparison of categorical variables between patients with and without synchronous lesions, we used Fisher test; in the case of numerical variables, Mann-Whitney test was used. Odds ratios (OR) with their corresponding 95\% CI for the comparison of bowel cleansing quality between index and therapeutic colonoscopies, a Wilcoxon Signed-Rank test was used. A $P$ value of less than 0.05 was considered to be statistically significant. We hypothesized that a significant proportion of patients would have an unidentified synchronous lesion $(35 \%)$, hence the estimated sample size needed would be 70 patients

\section{RESULTS}

During the study period, we identified 178 patients who required EMR of a colorectal lesion. As shown in FIGURE 1, 70 patients finally fulfilled inclusion criteria and were considered for further

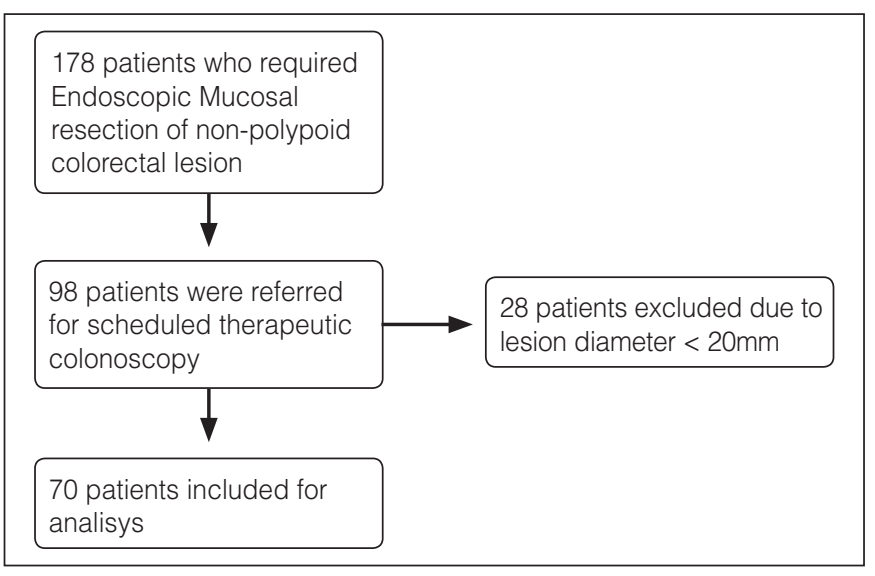

FIGURE 1. Flow chart showing patient selection process. analysis. All colonoscopies were performed at our Endoscopy Unit by seven experienced endoscopists; all of them have an adenoma detection rate of over $25 \%$. TABLE 1 shows the main features of included patients as well as their index lesions. As it can be observed, median size of index lesions was $25 \mathrm{~mm}(20-45)$. Eighty percent of these lesions were located in the right colon. Major adverse event rate (major bleeding or colonic perforation) was $2.85 \%$. No loss of follow up was reported.

TABLE 1. Main characteristics of included patients.

\begin{tabular}{lc}
\hline Variable & $\%(\mathbf{n} / \mathbf{N})$ \\
\hline Age* & $64(28-69)$ \\
Gender $(\% \mathrm{M})$ & $40(28 / 70)$ \\
Median size $(\mathrm{mm}) *$ & $25(20-45)$ \\
Location & \\
$\quad$ Right colon & $80(56 / 70)$ \\
$\quad$ Left colon & $14.28(10 / 70)$ \\
$\quad$ Rectum & $5.71(4 / 70)$ \\
*Values expressed as median and range. &
\end{tabular}

FIGURE 2 shows the histological findings of index lateral spreading tumors. The most common finding was tubular adenoma (46\%). Overall, $38.57 \%$ of patients showed at least one synchronous lesion which was not identified in the previous colonoscopy: $70 \%$ were categorized as flat non-polypoid lesions with a median size of $10 \mathrm{~mm}(5-16)$ and $50 \%$ were located in the right colon. It is noteworthy that the most common histological finding in this case was serrated adenoma $(35.71 \%)$, followed by tubular adenoma $(34.28 \%)$, tubule-villous adenoma with high-grade dysplasia (15.71\%) and hyperplastic polyps (14.28\%).

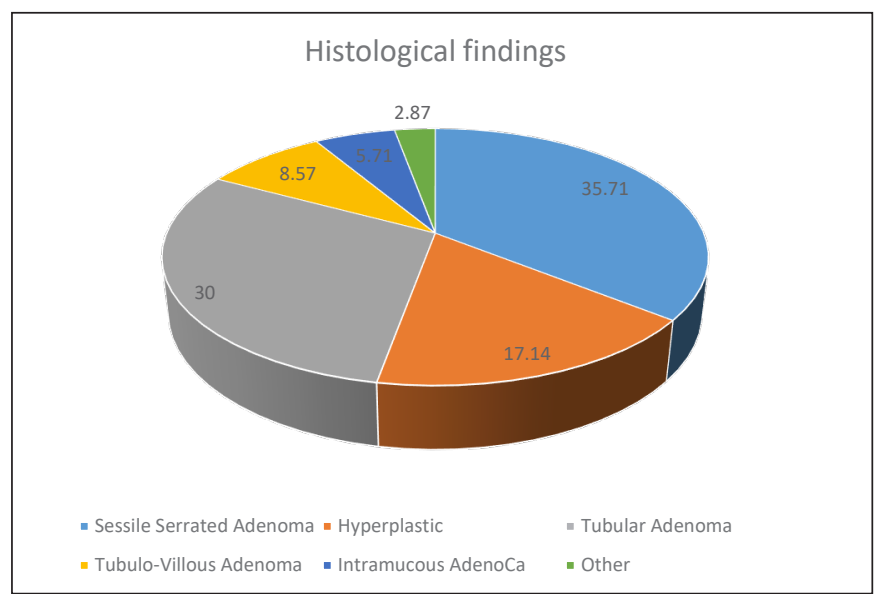

FIGURE 2. Histological findings of lateral spreading tumors.

TABLE 2 shows the comparison of clinical features between patients with and without synchronous lesions. There were no differences in terms of age and gender between groups. Additionally, both cecal intubation rate as well as bowel cleansing quality were similar. When comparing bowel cleansing quality between diagnostic colonoscopies and therapeutic colonoscopies, we also found no difference [Boston BPS 8 (7-9) vs 8 (8-9), $P=0.8$ ]. Interestingly, patients with synchronous lesions on therapeutic colonoscopy had 
TABLE 2. Comparison of patients with and without synchronous colorectal lesions.

\begin{tabular}{lccc}
\hline & $\begin{array}{c}\text { Patients with synchronous } \\
\text { lesion }(\% \mathbf{n} / \mathbf{N})\end{array}$ & $\begin{array}{c}\text { Patients without synchronous } \\
\text { lesion }(\%, \mathbf{n} / \mathbf{N})\end{array}$ & OR (CI95\%) \\
\hline Age* & $60(39-67)$ & $63(48-68)$ & N/A \\
Gender $(\% \mathrm{M})$ & $37.07(10 / 27)$ & $41.86(18 / 43)$ & 0.2 \\
Boston Bowel Preparation Scale** & $8(8-9)$ & $8(8-9)$ & $0.81(0.31-2.19)$ \\
Serrated adenoma as index lesion & $51.85(14 / 27)$ & $25.58(11 / 43)$ & N/A \\
\hline
\end{tabular}

*Expressed as median and range. **Expressed as median and $25-75$ interquartile range.

a significantly higher proportion of serrated adenomas as index lesions when compared to patients without synchronous lesions [51.85\% vs $25.58 \%$, OR 3.13 (1.13-8.68), $P=0.03$ ].

\section{DISCUSSION}

According to our results, patients with large lateral spreading tumors present an increased risk of synchronous lesions, which is a relevant finding with significant implications on the management and surveillance of these patients.

Patients with large lateral spreading tumors constitute a special population, since these lesions are at increased risk of developing CRC and endoscopic treatment can be challenging ${ }^{(15)}$. Nevertheless, EMR is regarded as a potential curative procedure which can replace surgery in most cases ${ }^{(16)}$. It is important, however, to bear in mind that EMR is associated with a non-neglectable risk of recurrent disease, a risk that seems to be higher if piecemeal EMR is performed ${ }^{(17)}$.

It is a common practice to refer patients with a diagnosis of a large lateral spreading tumor to a second endoscopic procedure for EMR. This scenario allows for further exploration of the colon, which theoretically would decrease the odds of lack of adenoma detection. It is interesting that a high proportion of these patients showed synchronous lesions when exploring the colon after index colonoscopy. These findings are consistent with previous studies ${ }^{(18)}$, suggesting an elevated adenoma miss rate in these particular population.

It is worth mentioning that the conditions under which both indez and therapeutic colonoscopies were performed did not differ significantly: the same experienced endoscopists, using the same equipment, with similar cecal intubation rates as well as similar bowel cleansing quality. This finding excludes the possibility that adenoma miss rate may be due to differences in terms of colonoscopic quality indicators.

In our study, a significant association between serrated adenomas as index lesions and the odds of synchronous lesions was observed. In previously published studies, the detection of large serrated adenomas at screening colonoscopy has been shown to be independently associated with an increased risk of synchronous advanced neoplasia $^{(19)}$. This has significant implications in terms of surveillance, since patients with a diagnosis of these type of lesions should be followed closely. Coincidentally, sporadic sessile serrated adenomas have been associated with an increased risk of metachronous advanced lesions ${ }^{(20)}$. Our study confirms that the finding of a serrated adenoma - or at least, a lesion that macroscopically could resemble a serrated adenoma - has an increased risk of synchronous lesion that may be easily overlooked.

There are some possible reasons that could explain the high proportion of synchronous lesions missed during index colonoscopy. First of all, the vast majority of these lesions were non-polypoid and located in the right colon: these type of lesions can be easily overlooked even if experienced hands. On the other hand, the find- ing of a large lateral spreading tumor may produce an effect on the endoscopist that may undermine the exhaustive search of further lesions - a phenomenon described as "one-and-done" effect. This is proposed as one of the reasons why adenoma detection rate as a sole quality indicator of the endoscopist performance in screening colonoscopy may not be sufficient: according to recently published studies, the mean number of adenomas per patient as well as the rate of proximal adenomas or the adenoma miss rate can vary in a significant way among endoscopists with similar adenoma detection rates ${ }^{(21)}$. Our study highlights the importance of being extremely cautious when finding a large lateral spreading tumor and not to undermine the need to perform a thorough exploration of the colonic mucosa - regardless the decision of programming a further therapeutic colonoscopy for the resection of the aforementioned lesion.

Our study has some limitations that should be mentioned. First of all, it is a retrospective study, with all the logical limitations that studies of this kind have. Some relevant quality indicators such as withdrawal time was not registered. On the other hand, we included a relatively scarce number of patients, since most of the lesions identified had a diameter $<20 \mathrm{~mm}$. Nevertheless, there is a relatively scarce amount of evidence on this subject to date, and the findings have a profound impact on the management of these patients: it should be noticed that the identification of a large lateral spreading tumor carries an increased risk of synchronous lesions, most of them non-polypoid lesions and as a consequence, these patients should be subject to thorough exploration of the colonic mucosa, especially of the right colon. On the other hand, patients referred for EMR of such lesions should undertake a complete colonic exploration, regardless of the lesion location or the quality of the previous endoscopy. Last but not least, these patients with a high risk of synchronous lesions may benefit from a shorter surveillance interval.

In conclusion, we found a high proportion of patients referred for EMR of large lateral spreading tumors with synchronous colorectal lesions, especially when index lesion is a serrated adenoma. Hence, these special population should undergo an exhaustive and thorough screening procedure as well as a special surveillance strategy.

\section{Authors' contribution}

Torella MC, Duarte B: patient data search. Torella MC, Zubiaurre I: study design. Lasa J: statistical analysis and manuscript draft ellaboration. Lasa J, Zubiaurre I: critical review of final draft.

\section{Orcid}

Maria Constanza Torella. Orcid: 0000-0001-7730-2638.

Belén Duarte. Orcid: 0000-0002-9254-2100.

Mariano Villarroel. Orcid: 0000-0002-6228-6310.

Juan Lasa. Orcid: 0000-0002-8995-1659.

Ignacio Zubiaurre. Orcid: 0000-0001-8334-9934. 
Torella MC, Duarte B, Villarroel M, Lasa J, Zubiaurre I. Aumento do risco de lesões colorretais síncronas em pacientes encaminhados para ressecção endoscópica da mucosa de tumores de propagação lateral. Arq Gastroenterol. 2019;56(3):276-9.

DESCRITORES - Contexto - A ressecção endoscópica de mucosa é uma das alternativas terapêticas frequentes para grandes tumores colorretais de propagação lateral. Há poucos dados sobre a prevalência de lesões síncronas nesses pacientes. Objetivo - Descrever a prevalência de lesões colorretais síncronas em pacientes encaminhados para ressecção endoscópica da mucosa de tumores de disseminação lateral $>20$ mm. Métodos - Realizou-se a revisão de banco de dados endoscópicos de nosso departamento e foram identificados pacientes adultos encaminhados para a ressecção de um tumor colorretal com propagação lateral > $20 \mathrm{~mm}$ e que tiveram colonoscopia diagnóstica realizada até seis meses antes. Estimou-se a proporção de pacientes com pelo menos uma lesão síncrona. As seguintes características foram comparadas entre pacientes com e sem lesões síncronas: idade, sexo, qualidade da preparação intestinal e intubação cecal pelo índice de colonoscopia e adenoma serrilhado como lesão índice. Resultados - De dezembro de 2016 a novembro de 2017, identificamos 70 pacientes que preencheram os critérios de inclusão. O tamanho mediano das lesões foi de 25 mm (20-45). Foram $80 \%$ situados no cólon direito e 35,71\% eram adenomas serrilhados. A taxa de lesão síncrona foi de 38,57\%. A qualidade da preparação intestinal foi semelhante em ambos os grupos comparando-se os índices e colonoscopia terapêutica. Pacientes com lesões síncronas apresentaram maior proporção de adenoma serrilhado como lesão índice do que pacientes sem lesões síncronas $[51,85 \%$ vs $25,58 \%$, or 3,13 $(1,13-8,68), P=0,03]$. Conclusão - Encontramos alta prevalência de lesões síncronas entre pacientes com grande tumor de propagação lateral colorretal. Este risco parece ser aumentado se as lesões índice forem adenomas serrilhados.

DESCRITORES - Neoplasias colorretais. Ressecção endoscópica de mucosa. Colonoscopia.

\section{REFERENCES}

1. Parkin DM, Bray F, Ferlay J, Pisani P. Global cancer statistics, 2002. CA Cancer J Clin. 2005;55:74-108.

2. Corley DA, Jensen CD, Marks AR, Zhao WK, Lee JK, Doubeni CA, et al Adenoma detection rate and risk of colorectal cancer and death. N Engl J Med. 2014;370:1298-306.

3. Nishihara R, Wu K, Lochhead P, Morikawa T, Liao X, Qian ZR, et al. Longterm colorectal cancer incidence and mortality after lower endoscopy. N Engl J Med. 2013;369:1095-105.

4. Zauber AG, Winawer SJ, O'Brien MJ, Lansdorp-Vogelaar I, van Ballegooijen M, Hankey BF, et al. Colonoscopic polypectomy and long-term prevention of colorectal-cancer deaths. New Engl J Med. 2012;366:687-96.

5. Rex DK, Petrini JL, Baron TH, Chak A, Cohen J, Deal SE, et al. Quality indicators for colonoscopy. Am J Gastroenterol. 2006;101:873-85.

6. Facciorusso A, Antonino M, Di Maso M, Barone M, Muscatiello N. Nonpolypoid colorectal neoplasms: classification, therapy and follow-up. World J Gastroenterol. 2015;21:5149-5157.

7. Hewett DG, Rex DK. Miss rate of right-sided colon examination during colonoscopy defined by retroflexion: an observational study. Gastrointest Endosc. 2011;74:246-252.

8. Anderson JC. Risk factors and diagnosis of flat adenomas of the colon. Expert Rev Gastroenterol Hepatol. 2011;5:25-32.

9. De Ceglie A, Hassan C, Mangiavillano B, Matsuda T, Saito Y, Ridola L, et al Endoscopic mucosal resection and endoscopic submucosal dissection for colorectal lesions: a systematic review. Crit Rev Oncol Hematol. 2016;104:138-55.

10. Pohl J, Halphen M, Kloess HR, Fischbach W. Impact of the quality of bowel cleansing on the efficacy of colonic cancer screening: a prospective, randomized, blinded study. PLoS One. 2015;10:e126067.

11. Kaminski MF, Regula J, Kraszewska E, Polkowski M, Wojciechowska U, Didkowska J, et al. Quality indicators for colonoscopy and the risk of interval cancer. N Engl J Med. 2010;362:1795-803.
12. Lee J, Park SW, Kim YS et al. Risk factos of missed colorectal lesions after colonoscopy. Medicine (Baltimore) 2017;96:e7468.

13. Papanikolau IS, Apostolopulos P, Tziatzios G, et al. Lower adenoma miss rate with FUSE vs conventional colonoscopy with proximal retroflexion: a randomized back-to-back trial. Endoscopy. 2017;49:468-75.

14. Kumar S, Thosani N, Ladabaum, Friedland S, Chen AM, Kochar R, Banerjee $\mathrm{S}$. Adenoma miss rates associated with a 3-minute versus 6-minute colonoscopy withdrawal time: a prospective, randomized trial. Gastrointest Endosc. 2017;85:1273-80

15. Hurlstone DP, Sanders DS, Cross SS, Adam I, Shorthouse AJ, Brown S, et al. Colonoscopic resection of lateral spreading tumors: a prospective analysis of endoscopic mucosal resection. Gut. 2004:53:1134-339.

16. Raju GS, Lum PJ, Ross WA, Thirumurthi S, Miller E, Lynch PM, et al. Outcome of EMR as an alternative to surgery in patients with complex colon polyps. Gastrointest Endosc. 2016;84:315.325.

17. Zhan T, Hielscher T, Hahn F, Hauf C, Betge J, Ebert MP, Belle S. Risk factors for local recurrence of large, flat colorectal polyps after endoscopic mucosal resection. Digestion. 2016;93:311-7.

18. Bick BL, Ponugoti PL, Rex DK. High yield of synchronous lesions in referred patients with lateral spreading colorectal tumors. Gastroint Endosc. 2017;85:228-33.

19. Ng SC, Ching JY, Chan VC, Wong MC, Tang R, Wong S, et al. Association between serrated polyps and the risk of synchronous advanced colorectal neoplasia in average-risk individuals. Aliment Pharmacol Ther. 2015;41:108-15.

20. Pereyra L, Zamora R, Gomez EJ, Fischer C, Panigadi GN, González R, et al. Risk of metachronous advanced neoplastic lesions in patients with sporadic sessile serrated adenomas undergoing colonoscopic surveillance. Am J Gastroenterol. 2016;111:871-8.

21. Wang HS, Pisegna J, Modi R, Liang LJ, Atia M, Nguyen M, et al. Adenoma detection rate is necessary but insufficient for distinguishing high versus low endoscopist performance. Gastrointest Endosc. 2013;77:71-8. 